\title{
EMPLOYEE EMPOWERMENT AND EMPOWERING LEADERSHIP: A LITERATURE REVIEW
}

\section{VU MINH HIEU}

Faculty of Business Administration, Van Lang University, Vietnam Email: vuminhhieu@vanlanguni.edu.vn or hieuvu2000@gmail.com

\begin{abstract}
Empowerment fosters employee's creativity, quality of work-life, spirit of teamwork and organisational effectiveness. organisations do not only need to empower employees but should also encourage empowering leadership. Empowering leadership connotes the sharing of power and motivating employees to crave for superior performance. This paper focuses on literature in the employee empowerment and empowering leadership contexts. Considering the role people play in organisations, it is important to understand the impact of employee empowerment and empowering leadership on organisational outcomes. The author used historical data and findings from previous studies to draw insight on the subject. Based on our review, it was observed that employee empowerment fosters employee performance, job satisfaction, organisational commitment, customer satisfaction, productivity and business growth. Empowering leadership have been examined from the structural and motivational theoretical perspective. Several studies lend credence to the positive influence of empowering leadership on employees' psychological empowerment. The author proposed some recommendations for managers to implement.
\end{abstract}

Keywords: empowerment, empowering leadership, delegation, obsession passion

\section{INTRODUCTION}

All the present organisations require knowledge and skilled employees to sustain superior performance. More so, intense competition in various markets calls for committed employees. In this context, employee empowerment is an important success factor for firms. Empowerment enhances employees' trust, commitment and productivity (Nwachukwu, 2016). Empowerment promotes employee participation in decision making, good idea generation and execution. It has been argued that empowerment serves as a guideline that foster effectiveness, productivity and employee satisfaction. By accepting more responsibilities employees can be motivated to grow their competencies and capabilities. Employee empowerment focuses on sharing power/responsibility and eliciting the commitment of organisations workforce. Committed and loyal employees achieve organisational objectives (Locke \& Latham, 1990), and are more 
productive, possess higher responsibility and job satisfaction (Karim \& Rehman, 2012). Organisations with committed employees experience low labour turnover, satisfied and highly motivated people (Sahoo, Behera, \& Tripathy, 2010). Empowering leadership connotes "sharing power" and motivating employees to put in exceptional performance in their work (Zhang \& Bartol, 2010). Extant literature suggests that empowering leadership influence employee work performance and routine task performance (Ahearne, Mathieu \& Rapp, 2005; Amundsen \& Martinsen, 2014; Vecchio, Justin \& Pearce, 2010), creative performance (Amundsen \& Martinsen, 2015; Zhang \& Bartol, 2010; Zhang \& Zhou, 2014). Other scholars did not report a positive effect of empowering leadership (Cheong, Spain, Yammarino \& Yun, 2016; Humborstad, Nerstad \& Dysvik, 2014). For empowering leadership to be effective, the delegated responsibilities must be perceived as motivating by employees. The goal of the paper is to examine the concepts of employee empowerment and empowering leadership based on the review of relevant literature and propose recommendations to managers.

\section{METHODOLOGY}

The paper uses the systematic literature review method to achieve the study goal. The author analysed full-text articles obtained from SCOPUS, EBSCO and Google Scholars. The search criteria include: both empirical and theoretical papers, keywords: employee empowerment and empowering leadership. After irrelevant articles were removed, 45 articles were selected and analysed. This paper is organized as follows: The next section presents an overview of strategic management in tourism, tourism in African and the nature of tourism in selected African countries. Followed by the analyses of the economic contribution of tourism in sample African countries. Finally, conclusions and recommendations are presented.

\section{FINDINGS AND DISCUSSION}

\section{Conceptualising employee empowerment}

The concept of employee empowerment has been defined by scholars in different ways. Most of them agree that empowerment connotes giving employees discretion over certain task-related activities. According to Randolph (1995) employee empowerment is the "transfer of power" from the employer to the employees. Employee empowerment focuses on developing trust, motivation, and participating in decision-making (Meyerson \& Dewettinck, 2012). Empowerment gives an employee the authority to make decisions (Saif \& Saleh, 2013), thus, they can be motivated, committed, satisfied and help in dealing with customer needs (Jacquiline, 2014). Huxtable (1994) asserts that employee empowerment is giving authority to employees to deal with daily job activities. Management scholars have expanded the conceptualisation of empowerment beyond discretionary power and job autonomy. For instance, Spreitzer (1995) opines that empowerment should be viewed from a psychological perspective reflecting an individual's feelings of self-control and self-efficacy. Arnold, Arad, Rhoades and Drasgow (2000) contend that empowerment should focus on the nature of the association between managers and their subordinates. There are four perspectives to empowerment (Wooddell, 2009; Herrenkohl et al., 1999): (1) common attitude (success in meeting goals, customer-oriented, goal clarity), (2) The organisational support (authority in decision making, taking responsibility team effectiveness, risk-taking and employee intention toward customer orientation), (3) knowledge and learning (encouraging for changing, skills and tendency for change, trust, communication with customers), (4) fundamental recognition (the 
awareness and knowledge of reward system). Spreitzer (1995) identifies five cognitive dimensions which managers can use to empower employees. He opines that managers need to create five characteristics in employees to empower them: Sense of competence, sense of selforganised, sense of being effective, sense of being meaningful or important and sense of trust others. Sense of Competence (self-effectiveness) connotes a person's belief that another person can do his/her tasks. It has been argued that this attribute is the most important because it determines if people try hard or persevere to do their duties or not. Sense of self-organized (Sense of having the right of selection) suggests that self-organised people perform their tasks voluntarily not by force. They see themselves as self-starters and very active persons. Sense of being effective connotes the ability of a person to effectively manage administrative, strategic and operational results and consequences (Spreitzer, 1995). When people are empowered, they can control and influence the environment they work or they can change the results. Sense of being meaningful or important explain the reason people pursue valuable and important job goals. Sense of being meaningful or important suggest, that empowered people use their time and energy worthfully. Sense of trust others means the trust between managers and subordinates which is linked to the trust in interests, competency and trust others. These five characteristics can enable managers to successfully empower their employees.

\section{Employee empowerment strategies}

Empowerment strategies and techniques which provide a feeling of support for subordinates and increase their confidence will be effective on reinforcing belief (Barsi, Ziglari \& Abadi, 2013). Scholars suggest that employee empowerment strategies include management leadership and commitment, communication, employee inclusion, reward system, clearly defined goals, managerial strategies, training, delegation of authority, formation of bipartite committees, sense of trusteeship, employees suggestion scheme and interaction with top executives (e.g Sahoo \& Das, 2011). Arguably, effective management leadership and commitment is needed to maintain employee empowerment. Employees will demonstrate a high level of commitment if they perceive that top management show commitment by providing adequate resources. Top management must communicate the company mission and objective to employees so that they will know what value to add to the organisation. Indeed, communication supports the firm culture, foster coordination and facilitate decision making consistent with the strategic objectives of the organisation. Kathuria and Davis (2001) note that organisation need to involve employees in critical thinking, basic leadership and methodology details to enhance performance. Inclusion allows employees to secure new information and understand what is expected of them. Arguably, a robust reward system is important to empower employees and motivate them to put in their best. Employees are empowered and motivated when their organisations set clear and challenging goals. Managers should create an environment that supports employees to do everything they want desirously and intentionally. Managerial strategies such as delegation, participating in decision making and leadership style can promote employee empowerment. Training will motivate employees to participate more actively by improving their confidence level. Arguably, employees training should focus on total quality, decision making, customer care and employee relations. Employee training has been associated with a couple of benefits such as lower costs, reduced turnover and absenteeism, increased revenues, employee satisfaction and flexibility empowerment. Delegation of authority can enable an organisation to nurture hidden talents and competencies to meet the business need. Formation of bipartite committees will promote healthy employee relations climate and superior organisational performance. Sense of trusteeship can motivate employees to achieve 
both organisational goals and individual desires and needs. Employees suggestion scheme provides employees with the opportunity to influence managerial decision making and involve themselves in organisation building activities. Interaction with top executives is the right platform for employees to raise several issues, offering their views, and suggestions for the survival and sustainability of the organisation.

\section{Effects of employee empowerment}

According to Kumar and Kumar (2017) employee empowerment is a motivational strategy that promotes employees' sense of satisfaction towards their job and organisation. They add that empowered employees are happy with the training they received, self-development programmes, employee meetings, their participation in the various activities and consideration of their ideas and opinion. Extant literature suggests that employee empowerment has a direct influence on employee performance (Meyerson \& Dewettinck, 2012), job satisfaction (Raza, Mahmood, Owais \& Raza, 2015; Wadhwa \& Verghese, 2015), and organisational commitment (Gholami, Soltanahmadi, Pashavi \& Nekouei, 2013; Insan, Astuti, Raharjo \& Hamid, 2013; Kun, Hai-yan \& Lin-li, 2007). Mukwakungu, Mankazana \& Mbohwa (2018) found that employee empowerment significantly influences customer satisfaction, quality improvement and organisational effectiveness. They conclude that organisations should give attention to the work environment because employees working conditions foster productivity. Nadeem et al. (2018) find that a significant relationship exists between employee empowerment and organisational performance. Celik et al. (2014) demonstrate that employee empowerment fosters organisational creativity and innovativeness among firms in Konya Organized Industrial Zone, Turkey. They concluded that employee empowerment promotes organisational creativity and innovativeness at the same time and managers should adopt a systematic approach to empower employees. Hunjra, UlHaq, Akbar and Yousaf (2011) submit that employee empowerment promotes achievement, productivity and business growth. As such, management should communicate the strategic direction of the firm to all employees to monitor its business performance. Hanayshahe (2016) reports that employee empowerment is connected to organisational commitment. They concluded that a higher employee's empowerment trait will lead to superior organisational performance. Laschinger, Finegan and Shamian (2002) suggest that creating an environment that supports the applications of empowerment at the workplace will enhance employees' commitment and organisational effectiveness. However, Nwachukwu (2016) reports that employee empowerment is not significantly related to the organisational culture of banks in Nigeria. He concludes that managers should be conscious of how they empower employees because it may weaken the organisation culture

\section{Effects of empowering leadership}

The concept of empowering leadership was primarily proposed by Manz and Sims (2001). They opine that leaders should lead employees to lead themselves "superleadership". Two different theoretical lenses have been used to examine empowering leadership; the structural empowerment and motivational perspectives. The structural empowerment theoretical lens emphasises on leaders sharing power and delegating tasks to employees (Leach, Wall \& Jackson, 2003; Conger \& Kanungo, 1988), while the motivational lens focuses on employee perceptions of empowerment (i.e., psychological empowerment), such as self-determination, and self-efficacy (Spreitzer, 1995; Conger \& Kanungo, 1988). Using the two lenses, Zhang and Bartol (2010), conceptualized empowering leadership as a process of delegating power to 
employees to increase their work motivation. Thus, empowering leadership involves sharing power and motivating employees to superior performance. Broadly speaking, empowering leadership, connotes improving the meaningfulness of work, encouraging employees participation in decision making, showing confidence in high performance, and promoting autonomy from bureaucratic barriers (Zhang \& Bartol, 2010; Arnold, Arad, Rhoades \& Drasgow, 2000). Empirical studies have shown that empowering leadership foster employee work performance by increasing one's job self-efficacy (Cheong et al., 2016; Ahearne et al., 2005), creative self-efficacy (Zhang \& Zhou, 2014) and career self-efficacy (Biemann et al., 2015). Scholars have examined the relationship between empowering leadership and employee work performance through different psychological mechanisms (Amundsen and Martinsen, 2015; Li et al., 2015; Raub \& Robert, 2010). Hao, He and Long (2017) find that empowering leadership has a positive indirect relationship with employee task performance and creative performance through harmonious passion, and a negative indirect association with employee task performance through obsessive passion. Even though empirical studies suggest that empowering leadership has a positive impact on employee work performance, some scholars have reported negative or non-significant relationships (e.g Cheong et al., 2016; Humborstad \& Kuvaas, 2013). Further, the connection between empowering leadership and employee passion for work has been examined. According to Chen et al. (2015) passion for work is a motivational state that involves the blend of affective, cognitive, and behavioural elements. It connotes a strong inclination toward an activity that people like and in which they spend time and energy (Vallerand et al., 2003). Vallerand et al. (2003) assert that obsessive passion is more likely to develop when employees experience an enforced internalisation of work. From the motivational perspective of empowerment, empowering leadership enhances employees' autonomous motivation (Conger \& Kanungo, 1988). Extant literature suggests that when leaders' empowerment expectations are more than employees' empowerment expectations, employees may experience low intrinsic motivation and high role stress (Humborstad et al., 2014; Humborstad \& Kuvaas, 2013). Similarly, leaders' high empowering behaviours may lead to work-induced tension for employees (Cheong et al., 2016) and work resistance (Maynard, Mathieu, Marsh \& Ruddy, 2007).

\section{CONCLUSIONS}

Empowerment foster creativity, innovativeness and entrepreneurial behaviour of employees. The 21st-century business environment demands employee empowerment and empowering leadership. Indeed, an empowering organisation focuses on autonomy, proper information and employee participation for organisational effectiveness. This paper reviews the employee empowerment and empowering leadership. The review suggests that empowerment encompasses common attitude organisational support, knowledge and learning and awareness and knowledge of reward system. Further, five characteristics that foster successful employee empowerment were identified; the sense of competence, sense of self-organized. sense of being effective, sense of being meaningful or important and sense of trust others. The review highlights some employee empowerment strategies; management leadership and commitment, communication, employee inclusion, rewarding system, clearly defined goals, managerial strategies, training, delegation of authority, formation of bipartite committees, sense of trusteeship, employee suggestion schemes and interaction with top executives. It was observed that employee empowerment has a positive influence on employee performance, job satisfaction, organisational commitment, customer satisfaction, productivity and business growth. However, employee empowerment may weaken a firm's organisational culture. 
Nonetheless, employee empowerment is crucial for firms that want to achieve superior performance. The review shows that structural and motivational perspective has been used to examine empowering leadership. Empowering leadership is consists of delegation and motivation. From the structural stance, empowering leadership has a positive influence on job self-efficacy, creative self-efficacy and career self-efficacy. It was also observed that empowering leadership impact on employee tasks performance through obsession passion and harmonious passion. Employee autonomous motivation is influenced by empowering leadership. Conversely, high empowering behaviour may have a negative effect on employee wellbeing and performance. It is obvious from the review that both employee empowerment and empowering leadership is needed to drive organisational success. The study, therefore, puts forward the following recommendations;

1. Managers should provide employees with the right mix of information, knowledge, power and rewards to energizes them for better performance.

2. Managers should provide employees with training and development opportunities to increase their competence and ability to handle challenging jobs. Training and development opportunities will encourage them to be involved in the organisation.

3. Managers must allow employees to have independence and feedback within the organisation as this can boost their confidence.

4. Organisations should adopt a participative management style where employees responsible for the tasks is involved in the decision-making process.

5. Managers must provide support, recognition and opportunities for employees as this can propel them to put in effort, time and energy towards achieving the organisational goals.

By implementing the above recommendations, managers can create an environment that empowers employees to increase the level of commitment for survival and sustainability of organisations. The present study focused on the review of prior literature on the subject, which somewhat limits its applicability. Nevertheless, it informs managers of the need to create a climate that supports employee empowerment. Additionally, it highlights the role empowering leadership plays in promoting employee tasks performance. Further studies should empirically examine other consequences and antecedents of employee empowerment and empowering leadership in varying contexts.

\section{REFERENCES}

[1]. Ahearne, M., Mathieu, J. \& Rapp, A. (2005). To empower or not to empower your sales force? An empirical examination of the influence of leadership empowerment behaviour on customer satisfaction and performance. Journal of Applied Psychology 90, 945-955.

[2]. Amundsen, S. \& Martinsen, Ø. L. (2014). Empowering leadership: Construct clarification, conceptualization, and validation of a new scale. Leadership Quarterly 25, 487-511.

[3]. Amundsen, S., \& Martinsen, Ø. L. (2015). Linking empowering leadership to job satisfaction, work effort, and creativity: The role of self-leadership and psychological empowerment. Journal of Leadership \& Organizational Studies 22, 304-323.

[4]. Arnold, J. A., Arad, S., Rhoades, J. A. \& Drasgow, F. (2000). The empowering leadership questionnaire: the construction and validation of a new scale for measuring leader behaviours. Journal of Organizational Behaviour, 21(3), 249-269. 
[5]. Barsi, M., Ziglari, F. \& Abadi, M. N. A (2013). Study Effective Factors on Employees' Empowerment by a Model Based on Conger \& Kanungo Model; Case Study: Social Security Organization of Bandar Abbas (Iran). International Journal of Academic Research in Accounting, Finance and Management Sciences, 3(4), 308-318.

[6]. Biemann, T., Kearney, E., \& Marggraf, K. (2015). Empowering leadership and managers' career perceptions: Examining effects at both the individual and the team level. Leadership Quarterly 26, 775-789.

[7]. Celik, A., Iraz, R. \& Selcuk (2014). The effects of employee empowerment applications on organizational creativity and innovativeness in enterprises: the case of oiz. European Scientific Journal, 10(10), 99-107.

[8]. Chen, X. P., Liu, D. \& He, W. (2015). Does passion fuel entrepreneurship and job creativity? A review and preview of passion research In Shalley, C. E., Hitt, M., Zhou, J. (Eds.), The Oxford handbook of creativity, innovation, and entrepreneurship: Multilevel linkages (pp. 159-176). Oxford, England: Oxford University Press.

[9]. Cheong, M., Spain, S. M., Yammarino, F. J \& Yun, S. (2016). Two faces of empowering leadership: Enabling and burdening. Leadership Quarterly, 27, 602-616.

[10]. Conger, J. A. \& Kanungo, R. N. (1988). The Empowerment Process: Integrating theory and practice. Academy of Management Review, 13(3), 471-482. 31.

[11]. Gholami, Z., Soltanahmadi, J. A., Pashavi, G., \& Nekouei, S. (2013). Empowerment as a basic step in upgrading organizational commitment and organizational citizenship behaviours: A Case study on public sector in Iran. World Applied Sciences Journal, 2l(11), 1693-1698.

[12]. Hanaysha, J. (2016). Examining the Effects of Employee Empowerment, Teamwork, and Employee Training on Organizational Commitment. 5th International Conference on Leadership, Technology, Innovation and Business Management Procedia - Social and Behavioural Sciences, 229(2016), 298 - 306

[13]. Hao, P., He, W., \& Long, L.-R. (2018). Why and When Empowering Leadership Has Different Effects on Employee Work Performance: The Pivotal Roles of Passion for Work and Role Breadth Self-Efficacy. Journal of Leadership \& Organizational Studies, 25(1), 85-100.

[14]. Herrenkohl, R., Judson, G. \& Heffner, J. (1999). Defining and measuring employee empowerment, Journal of Applied Behavioural Science 35, 373-385.

[15]. Humborstad, S. I. W. \& Kuvaas, B. (2013). Mutuality in leader subordinate empowerment expectation: Its impact on role ambiguity and intrinsic motivation. Leadership Quarterly, 24, 363-377.

[16]. Humborstad, S. I. W., Nerstad, C. G. L. \& Dysvik, A. (2014). Empowering leadership, employee goal orientations and work performance: A competing hypothesis approach. Personnel Review 43, 246-271.

[17]. Huxtable, N. (1994). Small business total quality. Springer Science \& Business Media.

[18]. Insan, A., Astuti, E. S., Raharjo, K., \& Hamid, D. (2013). The effect of empowerment of the organizational commitment and the job satisfaction of the employees of the National Electricity Company (Ltd.) in South Sulawesi Province Indonesia. Asian Transactions on Basic \& Applied Sciences, 3(4), 13-23.

[19]. Jacquiline, F. N. (2014). Employee empowerment and job satisfaction. Research journal of human resource, 2(2), 1-12.

[20]. Jones, A., Richard, B., Paul, D., Sloane, K., \& Peter, F. (2007). Effectiveness of teambuilding in organization. Journal of Management, 5(3), 35-37. 
[21]. Karim, F. \& Rehman, O. (2012). Impact of job satisfaction perceived organizational justice and employee empowerment on organizational commitment in semi-government organizations of Pakistan. Journal of Business Studies Quarterly, 3(4), 92-104.

[22]. Kathuria, R. \& Davis, E. (2001). Quality and workforce management practices: The managerial performance implication. Production and Operations Management, 10(4), 460-477.

[23]. Kumar, P. J. \& Kumar, A. A. (2017). Employee Empowerment - An Empirical Study. Global Journal of Management and Business Research: Administration and Management, 17(4), 59-64

[24]. Kun, Q., Hai-yan, S., \& Lin-li, L. (2007). The effect of empowerment on employees' organizational commitment: Psychological contract as mediator. Proceedings of Management Science and Engineering, 1493-1498.

[25]. Laschinger, H. K. S., Finegan, J. \& Shamian, J. (2002). The impact of workplace empowerment, organizational trust on staff nurses' work satisfaction and organizational commitment. Advances in Health Care Management, (3), 59-85.

[26]. Leach, D. J., Wall, T. D. \& Jackson, P. R. (2003). The effect of empowerment on job knowledge: An empirical test involving operators of complex technology. Journal of Occupational and Organizational Psychology 76, 27-52.

[27]. Li, S. L., He, W., Yam, K. C. \& Long, L. R. (2015). When and why empowering leadership increases followers' taking charge: A multilevel examination in China. Asia Pacific Journal of Management 32, 645-670.

[28]. Locke, E. A., \& Latham, G. P. (1990). A theory of goal setting \& task performance. Prentice-Hall, Inc.

[29]. Manz, C. C. \& Sims, H. P. (2001). The new super leadership: Leading others to lead themselves. San Francisco, CA: Berrett-Koehler. Mathieu, J. E., Maynard, M. T., Rapp, T., \& Gilson, L. (2008). Team effectiveness 1997-2007: A review of recent advancements and a glimpse into the future. Journal of Management 34, 410-476.

[30]. Maynard, M. T., Mathieu, J., Marsh, W. M. \& Ruddy, T. M. (2007). A multilevel investigation of the influences of employees' resistance to empowerment. Human Performance 20, 147-171.

[31]. Meyerson, G. \& Dewettinck, B. (2012). Effect of empowerment on employees performance. Advanced Research in Economic and Management Sciences 2, 40-46.

[32]. Mukwakungu, S. C., Mankazana, S. \& Mbohwa, C. The impact of employee empowerment on organizational performance in a flavours and fragrance manufacturing company in South Africa. Conference: GBATA's 20th Anniversary Annual International Conference at: Bangkok, Thailand

[33]. Nwachukwu, C. (2016). The impact of Performance Management and Employee empowerment on Organizational Culture of selected Banks in Nigeria. Ekonomika A Management, 2016(2).

[34]. Randolph, W. A. (1995). Navigating the journey to empowerment. Organizational Dynamics, 24(4), 19- 32.

[35]. Raub, S. \& Robert, C. (2010). Differential effects of empowering leadership on in-role and extra-role employee behaviours: Exploring the role of psychological empowerment. Human Relations 63, 1743-1770. 
[36]. Raza, H., Mahmood, J., Owais, M., \& Raza, A. (2015). Impact of employee empowerment on job satisfaction of employees in corporate banking sector employees of Pakistan. Journal of Applied Environmental and Biological Sciences, 5(2), 1-7.

[37]. Sahoo, C. \& Das, S. (2011). Employee empowerment: a strategy towards workplace commitment. European Journal of Business and Management, 13(11),46-54.

[38]. Sahoo, C. K., Behera, N. \& Tripathy, S. K. (2010). Employee empowerment and individual commitment: an analysis from integrative review of research. Employment Relations Record, 10(1), 40-56.

[39]. Saif, N. I. \& Saleh, A. S. (2013). Psychological empowerment and job satisfaction in Jordanian hospitals. International Journal of Humanities and Social Science, 3(16), 250-257.

[40]. Spreitzer, G. M. (1995). Psychological empowerment in the workplace: dimensions, measurement, and validation. Academy of Management Journal, 38(5), 1442-1465.

[41]. Vallerand, R. J., Blanchard, C., Mageau, G. A., Koestner, R., Ratelle, C., Léonard, M. \& Marsolais, J. (2003). Les passions de l'âme: On obsessive and harmonious passion. Journal of Personality and Social Psychology 85, 756-767.

[42]. Vecchio, R. P., Justin, J. E. \& Pearce, C. L. (2010). Empowering leadership: An examination of mediating mechanisms within a hierarchical structure. Leadership Quarterly 21, 530-542.

[43]. Wadhwa, D. S. \& Verghese, M. (2015). Impact of employee empowerment on job satisfaction and organizational commitment: An empirical investigation with special reference to selected cement industry in Chhattisgarh. International Journal in Management and Social Science, 3(3), 280-286.

[44]. Wooddell, V. (2009). Employee Empowerment, Action Research and Organizational Change: A Case Study, Organization Management Journal 6, 15-18.

[45]. Zhang, X. M. \& Bartol, K. M. (2010). Linking empowering leadership and employee creativity: The influence of psychological empowerment, intrinsic motivation, and creative process engagement. Academy of Management Journal 53, 107-128.

[46]. Zhang, X. M. \& Zhou, J. (2014). Empowering leadership, uncertainty avoidance, trust, and employee creativity: Interaction effects and a mediating mechanism. Organizational Behaviour and Human Decision Processes 124, 160-164. 